\title{
Decoração Cerâmica com Tecnologias de Jato de Tinta (Inkjet)
}

\author{
Yolanda Reiga, Vicente Lázaro ${ }^{a}, A n a ~ M a t e u^{a}$, Carlos Feliu \\ aTC, Universidad Jaume I, Av. Vicente Sos Baynat s/n, Castellón, 12006, España
}

\begin{abstract}
Resumo: Este artigo apresenta uma revisão sobre a tecnologia de impressão digital por jato de tinta aplicada ao setor cerâmico. É apresentado um histórico da tecnologia bem como as principais tecnologias de jato de tinta empregadas atualmente. $\mathrm{O}$ artigo também discute as mudanças que ocorreram no setor de desenvolvimento de produto, a tecnologia de cabeçote mais adequada à impressão cerâmica, os tipos de tintas e suas propriedades, e finaliza comentando sobre os desafios tecnológicos que devem ser superados para uma ampla aplicação desta nova tecnologia de decoração cerâmica.
\end{abstract}

Palavras-chave: decoração cerâmica, impressão digital, jato de tinta, tintas cerâmicas, inovação tecnológica.

\section{Introdução}

A história dos sistemas eletrônicos de impressão, e entre eles as impressoras, é muito recente. A primeira impressora elétrica para computador foi desenvolvida em 1953, embora somente pudesse escrever texto. Em 1959 a Xerox desenvolveu a fotocopiadora e em 1973 a Canon cria a fotocopiadora a cores. Foi a princípios de 1970 que a Centronics Corporation de Nashua fabricou a primeira impressora de matriz de pontos. Em 1978 foi criada a impressora de margarida, que somente podia escrever letras e números. Em 1980 é inventada a impressora a laser e em 1988 é incrementada para trabalhar a cores ${ }^{1}$.

Nos anos 1990 a impressora converte-se em um objeto comum em qualquer escritório ou posto de trabalho, chegando a estar na maioria dos lares que dispunham de um computador. Atualmente, o preço de uma impressora pode ser menor que o preço dos próprios consumíveis (tintas), sendo em algumas ocasiões mais econômico comprar um novo equipamento de impressão do que adquirir as tintas.

Quando todo este desenvolvimento translada-se para a área industrial para a fabricação de produtos seriados de forma contínua aparecem detalhes que dificultam a transferência ou desenvolvimento de tecnologia. Enquanto em setores como o de artes gráficas ou de fotografia a tecnologia de jato de tinta passa a ser chave no desenvolvimento dos mesmos, outros setores continuam com as técnicas tradicionais, devido à dificuldade que esta transferência a priori revela ${ }^{1}$.

É por esta razão que a tecnologia de impressão digital por jato de tinta é adiada para o setor cerâmico e só será uma realidade para a indústria cerâmica no ano de 1998, quando é fundada a empresa KERAJET, com o objetivo de fabricar industrialmente o primeiro protótipo de máquina de jato de tinta desenvolvida inteiramente para a decoração de peças cerâmicas.

Desde a apresentação deste primeiro protótipo já se passaram mais de 10 anos, durante os quais foi possível avaliar-se de maneira exemplar as dificuldades envolvidas no desenvolvimento e operacionalização de uma tecnologia. Apesar do consenso geral sobre as infinitas possibilidades e vantagens desta tecnologia, foi longo o caminho percorrido e muitas foram as dificuldades que as empresas que mais se dedicaram a ela tiveram de superar.

Atualmente ainda existem grandes desafios tecnológicos a serem superados, mas tanto a tecnologia quanto as tintas utilizadas alcançaram um grau de confiabilidade muito elevado, permitindo a obtenção de excelentes resultados de produção. Por outro lado, o pessoal responsável pelo funcionamento e uso destas máquinas começa a dispor de formação e experiência adequadas, o que permite otimizar as possibilidades técnicas e estéticas desta tecnologia, surpreendendo com novos desenhos e acabamentos em cada feira ${ }^{1}$.

Desta forma, o objetivo principal deste estudo é difundir entre as empresas do setor cerâmico o estado da arte desta tecnologia, assim como as vantagens da aplicação da tecnologia de impressão a jato de tinta na decoração de placas cerâmicas.

\section{Tecnologias de Jato de Tinta}

A impressão inkjet (ou jato de tinta) é um método de deposição de tinta sem contato. Em relação ao mecanismo de aporte de tinta é possível distinguir dois métodos: o jato de tinta contínuo e o jato de tinta sob demanda ${ }^{1-4}$. A Figura 1 mostra um esquema sobre os diferentes sistemas desenvolvidos para cada um dos métodos de deposição.

A informação digitalizada em um computador é usada para dirigir a tinta através de diminutos canais e assim formar padrões alfanuméricos ou de pontos. A tinta, transportada através destes canais, é transferida ao suporte, dando lugar à imagem impressa. Isto evita o uso de agentes intermediários que requerem um contato íntimo (pressão) com o suporte para poder realizar a transferência da tinta ${ }^{2}$.

\subsection{Jato de tinta contínuo}

O método de jato de tinta contínuo é mais concebido para impressão sobre papel. Utiliza princípios físicos, magnéticos e, sobretudo eletrostáticos. A informação da imagem é convertida em uma imagem latente e posteriormente cria-se um fluxo contínuo de gotas carregadas proporcionalmente à posição que devem ocupar no substrato ${ }^{2,3}$.

O cabeçote de impressão possui um gerador de gotas de tinta que pela ação de uma vareta oscilatória gera ondas de pressão ultrassônicas para romper o fluxo contínuo e formar as gotas individuais. Quando as gotas passam através de eletrodos adquirem carga elétrica intermitentemente. Uma vez carregadas, são passadas entre placas defletoras que determinam a alocação definitiva das mesmas sobre o substrato cerâmico. Isto é obtido pela variação da tensão do defletor sobre cada gota, o que condiciona a distância em que cada gota é desviada. Este efeito pode ser visualizado na Figura $2^{2,3}$.

As variáveis principais do processo são a carga das gotas, o campo elétrico aplicado e a velocidade inicial. A Tabela 1 mostra as vantagens e desvantagens desta técnica em relação ao jato de tinta sob demanda (seção 2.2). 


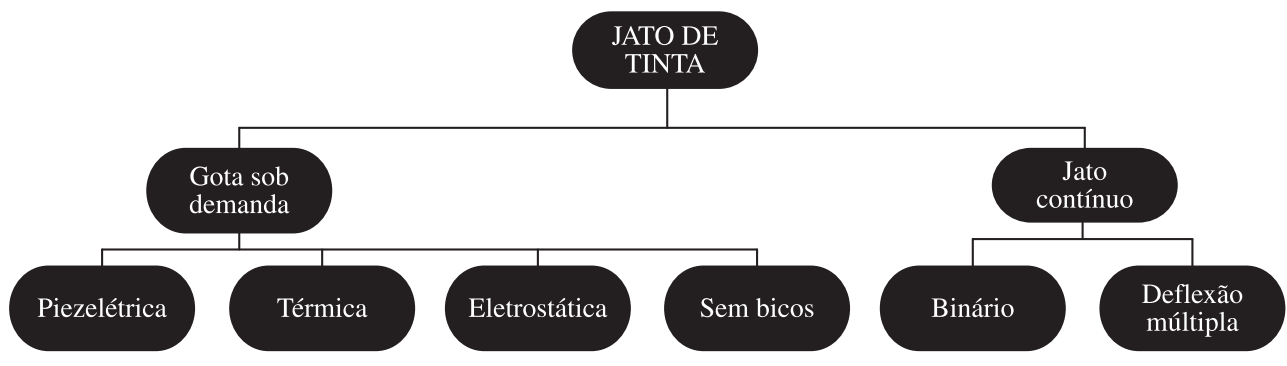

Figura 1. Tecnologias de jato de tinta.

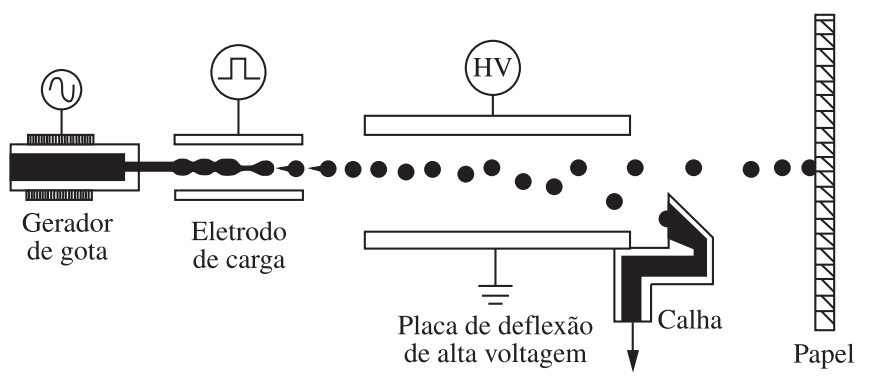

a) Sistema binário

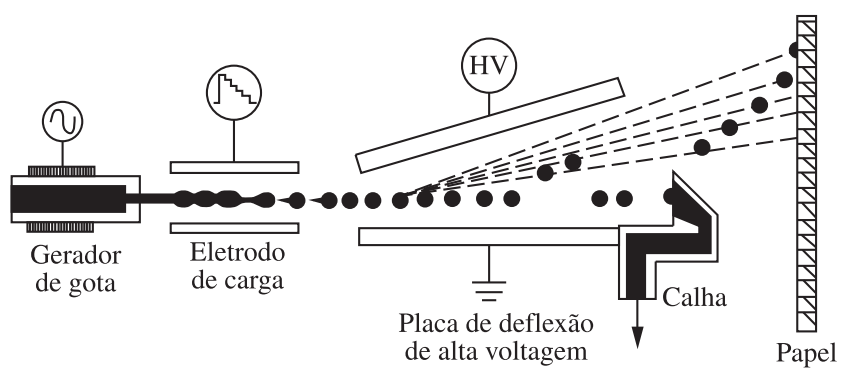

b) Sistema com deflexão múltipla

Figura 2. Esquema de funcionamento do sistema de jato contínuo: a) sistema binário; b) sistema com deflexão múltipla³

Tabela 1. Vantagens e desvantagens da impressão por jato de tinta contínuo ${ }^{2,3}$.

\begin{tabular}{ll}
\multicolumn{1}{c|}{ Vantagens } & \multicolumn{1}{c}{ Desvantagens } \\
\hline Tamanho de gotas variável entre $50-400 \mu \mathrm{m}$ & Elevado custo do sistema \\
\hline Freqüência de trabalho entre $50-150 \mathrm{kHz}$ & Manutenção complexa \\
\hline Elevada velocidade de impressão & Cabeçotes muito grandes \\
Alta quantidade de tinta depositada & Baixa definição gráfica da decoração \\
\hline Reprodutibilidade & \\
\hline
\end{tabular}

\subsection{Jato de tinta sob demanda}

Como o próprio nome indica o método de jato de tinta sob demanda caracteriza-se pela geração de cada gota unicamente no momento em que se requer. Atualmente, é o mais utilizado em escala industrial por diferentes razões, entre as quais a sua precisão, o menor tamanho de gota, o elevado número de gotas por polegada (dpi) e a sua simplicidade ${ }^{2,3}$

Com relação ao processo de geração das gotas é possível distinguir diversas técnicas de impressão sob demanda, conhecidas como: térmica, piezelétrica, eletrostática e "sem bico". A seguir é feita uma breve descrição de cada uma destas tecnologias.

\subsubsection{Jato de tinta por tecnologia térmica}

Consiste em superaquecer a tinta no interior do cartucho. Desta forma é favorecida a formação de bolhas, que são responsáveis pela saída da tinta ao exterior devido à pressão que exercem no interior do cartucho ${ }^{1-3}$.

Em uma primeira etapa é aplicada uma corrente em um resistor para aumentar a temperatura $\left(350-400^{\circ} \mathrm{C}\right)$. Isto provoca a nucleação de pequenas bolhas de vapor que crescem e unem-se formando uma única bolha de maior tamanho. A pressão de vapor obriga a tinta a sair do cartucho através dos bicos em forma de diminutas gotas que geram os pontos sobre a página. $\mathrm{O}$ vazio gerado pela tinta que foi expulsa empurra mais tinta para dentro dos bicos, gerando um fluxo constante de gotas, conforme seja necessário (Figura 3) ${ }^{2,3}$.

Com relação ao resistor utilizado para a formação da bolha e, portanto, da gota de tinta, este pode estar disposto em várias posições no cabeçote, como pode ser observado na Figura 4.
Para as disposições mostradas na Figura 4 podem ser encontrados no mercado até três tipos de cabeçotes térmicos distintos ${ }^{3,5}$ :

- Resistor na face oposta do bico (patenteado pela Hewlett-Packard);

- Resistor na parede do bico (patenteado pela Canon);

- Resistor em uma cavidade da parede do bico (patenteado pela Xerox).

\subsubsection{Jato de tinta por tecnologia piezelétrica}

Este método de impressão baseia-se no princípio piezelétrico, de modo que ao se submeter um material a uma determinada carga elétrica, este altera seu tamanho. Quando este material encontra-se dentro do cabeçote o aumento de tamanho origina uma pressão sobre a tinta, obrigando-a a sair ao exterior através do bico do cabeçote. O material piezelétrico mais utilizado é o PZT (titanato de chumbo e zircônio $)^{2,3,5}$.

Uma característica muito importante deste sistema é que o material piezelétrico sofre uma distorção proporcional ao campo aplicado, o que torna possível controlar com mais exatidão a quantidade de tinta projetada durante o processo. Isto possibilita a produção de gotas com maior velocidade.

Como não requer elevadas temperaturas, o processo de jato de tinta apresenta as seguintes vantagens ${ }^{3}$ :

- A seleção de tintas que podem suportar temperaturas de $200^{\circ} \mathrm{C}$ é muito limitada, e a tecnologia piezelétrica permite o uso de formulações de tinta que se adaptam melhor ao processo;

- Os bicos que não estão expostos a temperaturas extremas apresentam uma maior duração que os dos cartuchos térmicos tradicionais. 
Como ocorre para os cabeçotes térmicos, é possível encontrar no mercado distintas configurações de cabeçotes piezelétricos, como mostra a Figura 5.

Este tipo de cabeçote é o mais utilizado atualmente para o desenvolvimento de sistemas de decoração cerâmica, existindo uma ampla gama de fabricantes de cabeçotes piezelétricos para a aplicação de gotas de diversos tamanhos (10-100 pL) e com várias resoluções. Os principais fornecedores deste tipo de tecnologia para uso em decoração cerâmica são: Xaar, Spectra e Seiko ${ }^{3}$.

\subsubsection{Jato de tinta por tecnologia eletrostática}

O terceiro sistema de impressão é o jato de tinta por tecnologia eletrostática. Consiste na geração de uma carga elétrica induzida por um campo magnético, de modo que esta carga seja superior à tensão superficial da tinta, formando assim uma gota. Esta tecnologia permite regular o campo elétrico aplicado para gerar gotas de vários tamanhos. Pode-se ver um esquema do processo na Figura 6 e as características das gotas formadas na Tabela $2^{3,5}$.

\subsubsection{Jato de tinta sem bicos}

Por último, a tecnologia descrita nesta seção é conhecida pelo nome "nozzle-free inkjet", ou jato de tinta sem bico. Como se supõe, é diferente das demais tecnologias descritas anteriormente pela ausência dos bicos ${ }^{3,5}$.

Esta tecnologia consiste na obtenção de gotas a partir da emissão de ultra-som. Devido à convergência das ondas ultra-sônicas na superfície da suspensão (tinta), são geradas pequenas gotas de líquido. Quando a força da radiação (ultra-som) é maior que a tensão superficial da suspensão, há a geração de uma gota independente do restante da suspensão e que se deposita sobre a superfície do substrato, Figura $7^{6}$.

O processo de impressão desenvolve-se de forma similar aos dispositivos piezelétricos ou térmicos, mas sem o emprego de bicos, evitando-se assim possíveis problemas de entupimento. Além disto, o sistema de jato de tinta sem bico ("nozzle-free") permite a obtenção de gotas com distintos tamanhos, unicamente regulando-se a frequência das ondas acústicas.
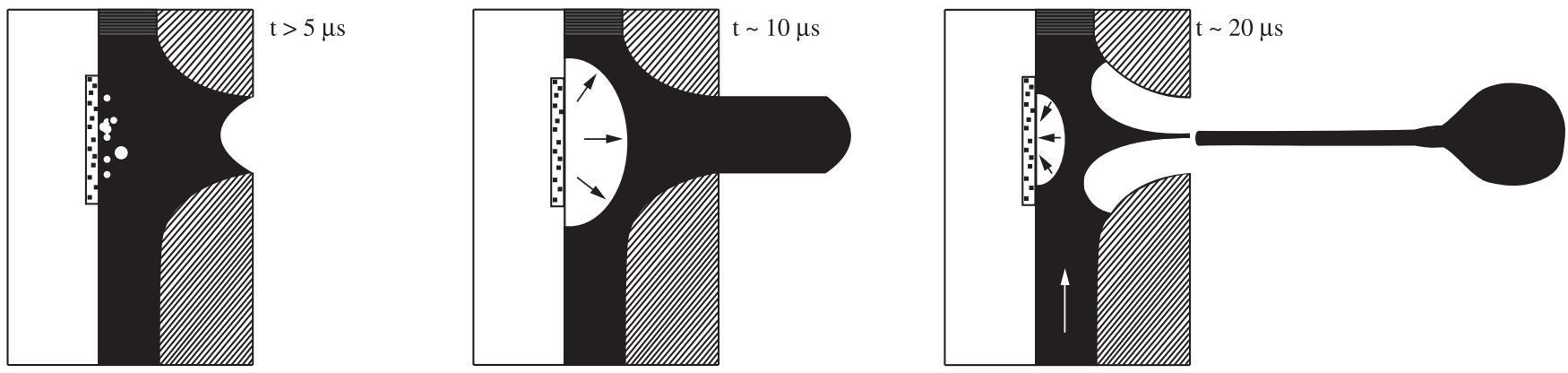

Figura 3. Funcionamento do sistema e formação da gota ${ }^{3}$.

Em uma cavidade

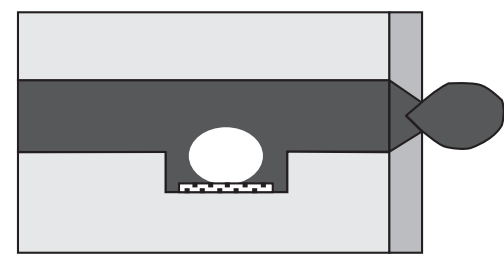

$\mathrm{Na}$ parede lateral

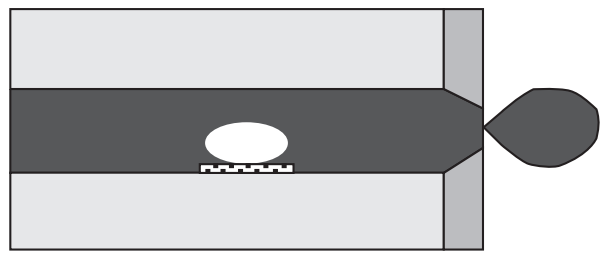

$\mathrm{Na}$ face oposta

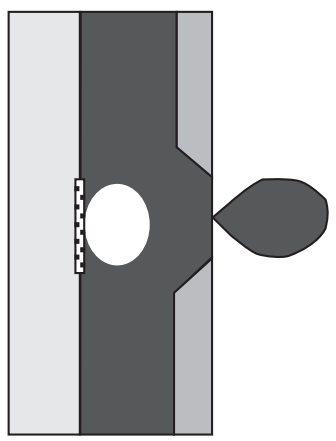

Figura 4. Posição do resistor nos cabeçotes térmicos 5 .
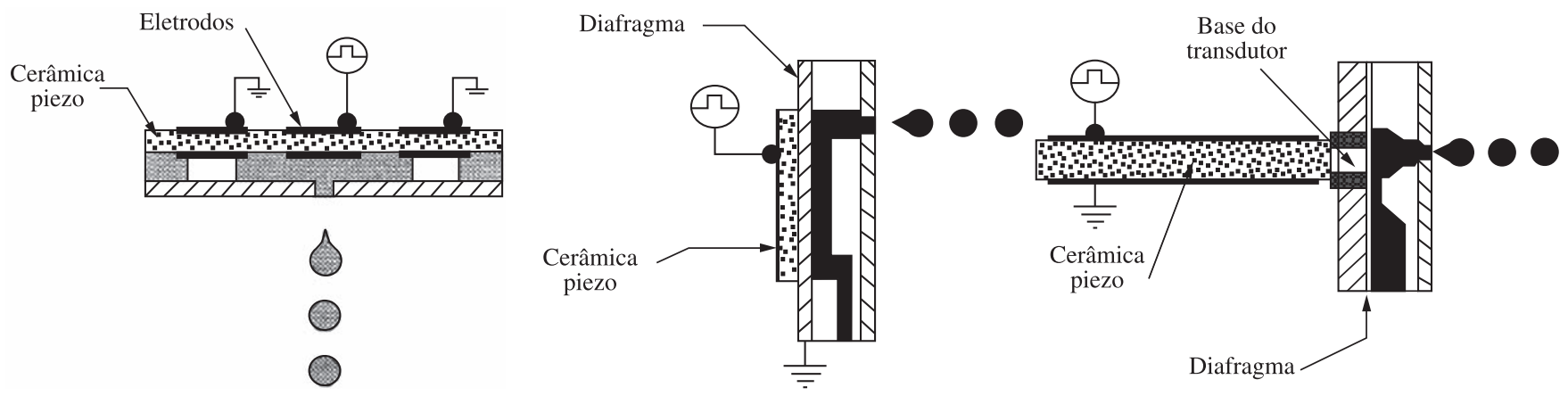

Figura 5. Diferentes arquiteturas de um cabeçote piezelétrico ${ }^{3}$. 
a) Descanso

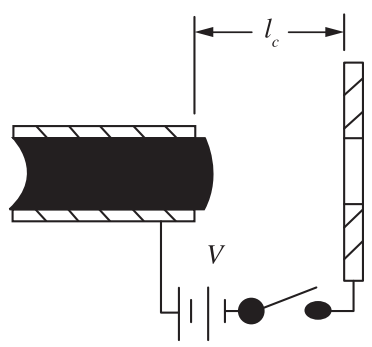

b) Excitação

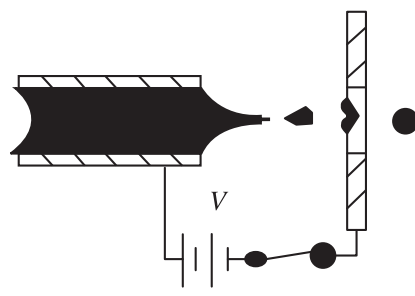

c) Retração

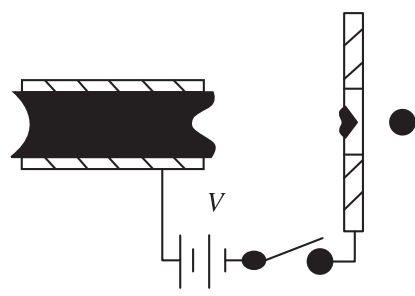

Figura 6. Cabeçote de jato de tinta eletrostático 5 .

Uma vantagem adicional frente aos sistemas de impressão convencionais é a possibilidade de trabalhar com suspensões de elevada viscosidade, mesmo quando a suspensão é muito densa. Contudo, ao se trabalhar com suspensões muito viscosas é necessário aumentar a potência do transdutor de ultra-som, pois as ondas são atenuadas ao atravessar a suspensão (viscosidade, geração de calor, vibração da estrutura). Para operar durante longos períodos de tempo é imprescindível refrigerar o transdutor e mantê-lo a uma temperatura constante $^{6}$.

\section{Diferenças no Desenvolvimento de Produto}

Até o momento, a utilização das técnicas convencionais de desenvolvimento de produto requeria um designer especializado em separação de tintas e um técnico especializado em efeitos e misturas de cores cerâmicas. Além disto, era necessária a realização de múltiplas provas em todas as fases (desenho, desenvolvimento, telas, cilindros, etc.) até chegar ao protótipo final. Como conseqüência de tudo gerava-se um elevado custo em horas de pessoal e materiais, aspecto pouco otimizado até então $0^{4,7,8}$.

Com a introdução da tecnologia de impressão inkjet na indústria cerâmica modifica-se drasticamente o antigo processo de desenvolvimento de produto. A nova abordagem oferece diferenças claras que se traduzem em importantes economias de custo, como por exemplo 7,8 :

a) Variação das tarefas a serem desenvolvidas tanto pelo designer como pelos técnicos de desenvolvimento de produto: $\mathrm{O}$ designer torna-se o protagonista. Deixa de desempenhar um trabalho mais metódico como é o processo de separação de

Tabela 2. Características das gotas formadas em função do campo elétrico aplicado ${ }^{3,5}$.

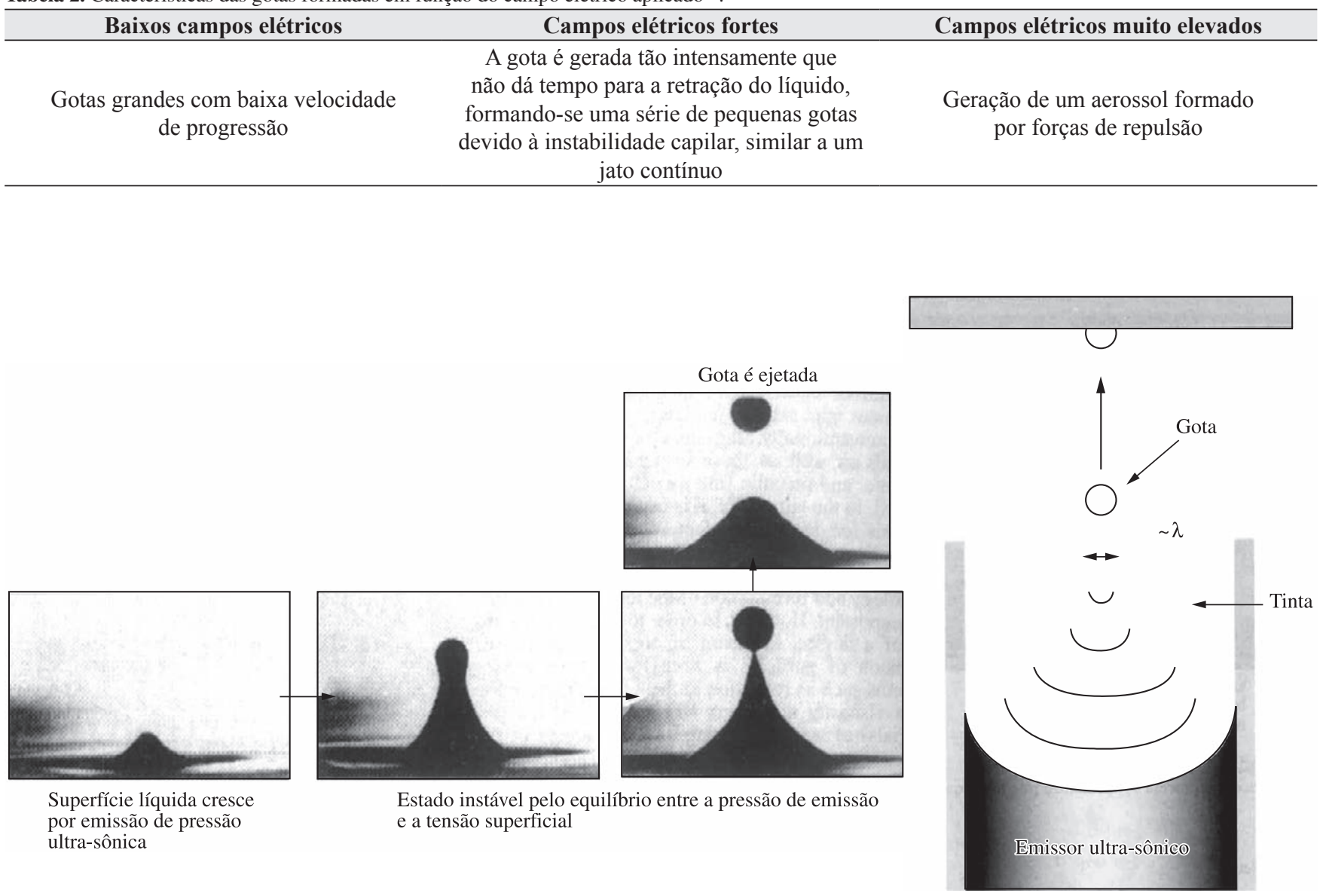

Figura 7. Aplicação da tecnologia de jato de tinta sem bico para formação da gota ${ }^{6}$. 
tintas para centrar-se na exploração de novas possibilidades estéticas que esta tecnologia oferece, bem como nos demais efeitos cerâmicos que não podem ser obtidos pelas técnicas de jato de tinta (granilhas, pellets, etc.). O papel do técnico em desenvolvimento de produto torna-se mais limitado. Agora não é mais necessário trabalhar as tintas, de modo que seu trabalho limita-se a buscar, utilizando os demais efeitos, um acabamento mais próximo ao resultado final buscado.

b) Introdução de novas tecnologias de calibragem e gestão de cores: A separação das tintas é realizada de forma automática graças ao aplicativo de trabalho. É necessária a calibração dos sistemas de visualização, ou seja, é necessário dispor de perfis de cor que tenham em conta ao menos o vidrado de base utilizado, com objetivo de se visualizar no monitor do equipamento de trabalho um resultado cromático mais próximo ao que se terá no produto final uma vez que seja queimado.

c) Redução ou desaparecimento das provas industriais: No processo tradicional, uma vez que se tenha o protótipo final é necessário realizar provas industriais, ou seja, preparar uma "pequena" quantidade de vidrados e tintas para produzir uma pequena quantidade de produto que normalmente requer alguns retoques devido às diferenças existentes na forma de se trabalhar em laboratório com relação ao processo industrial. Em algumas ocasiões e dependendo das tecnologias utilizadas (por exemplo, cilindros) a mudança é mais drástica e requer um maior número de provas. Uma vez obtidas as condições reais de trabalho na produção é necessária a gravação das telas ou rolos/cilindros definitivos para se obter uma pequena produção que permita realizar os correspondentes painéis promocionais. Entretanto, o sistema de jato de tinta simplifica drasticamente toda esta última fase, pois não se distingue mais entre provas de laboratório e de fabricação ao se utilizar a mesma máquina, não sendo necessários ajustes de variáveis. Além disto, não se requer a gravação de suportes físicos como telas serigráficas ou cilindros de impressão, que encarecem muito todo este processo.

\section{4. Últimos Avanços em Tecnologia Piezelétrica}

\subsection{Evolução na trama de imagens: escala estocástica de cinzas}

Como já se sabe, a necessidade da trama ou retícula de uma imagem fotográfica é uma realidade no momento que se requer sua transferência para um suporte físico a partir de um dispositivo virtual. Esta necessidade não é exclusiva das técnicas de impressão por jato de tinta ou outras técnicas digitais, mas é comum a todas as técnicas de estampagem (serigrafia, rotogravura, etc. $)^{7,9-11}$.

O tipo de trama varia em função do sistema de impressão utilizado, das tintas, da qualidade gráfica requerida, e mesmo do acabamento artístico desejado. De forma genérica existem dois tipos de tramas diferentes conhecidas como: amplitude modulada (AM) e freqüência modulada (FM), também chamada estocástica. A Figura 8 mostra o uso de cada uma destas tramas para a representação de uma mesma imagem.

Nas tramas de AM os pontos distribuem-se de forma ordenada em filas. Para se modificar o percentual de tinta modifica-se o tamanho do ponto, mantendo constante a distância entre eles. A um maior número de pontos por centímetro obtém-se uma maior resolução. É a trama tradicionalmente utilizada em serigrafia ${ }^{12-14}$.

Por sua vez, a trama FM apresenta pontos distribuídos de forma aparentemente aleatória, criando um efeito visual de degradado. Neste caso, para variar a intensidade da cor mantém-se constante o tamanho dos pontos e modifica-se a freqüência de sua distribuição, ou seja, o percentual da superfície ocupada por tais pontos. Neste processo os pontos da trama devem ter o menor tamanho permitido pelo equipamento de impressão.

Quando se pretende imprimir uma imagem colorida é necessário o uso de tintas de cores primárias (tradicionalmente CMYK) que são superpostas com diferentes imagens reticuladas. A imagem final é obtida pelo agrupamento de pontos ou gotas de tinta depositadas sobre o substrato ou suporte. O observador percebe somente uma tonalidade contínua, formada pela média dos tons, apesar de que tais imagens são compostas por uma infinidade de pontos discretos. A

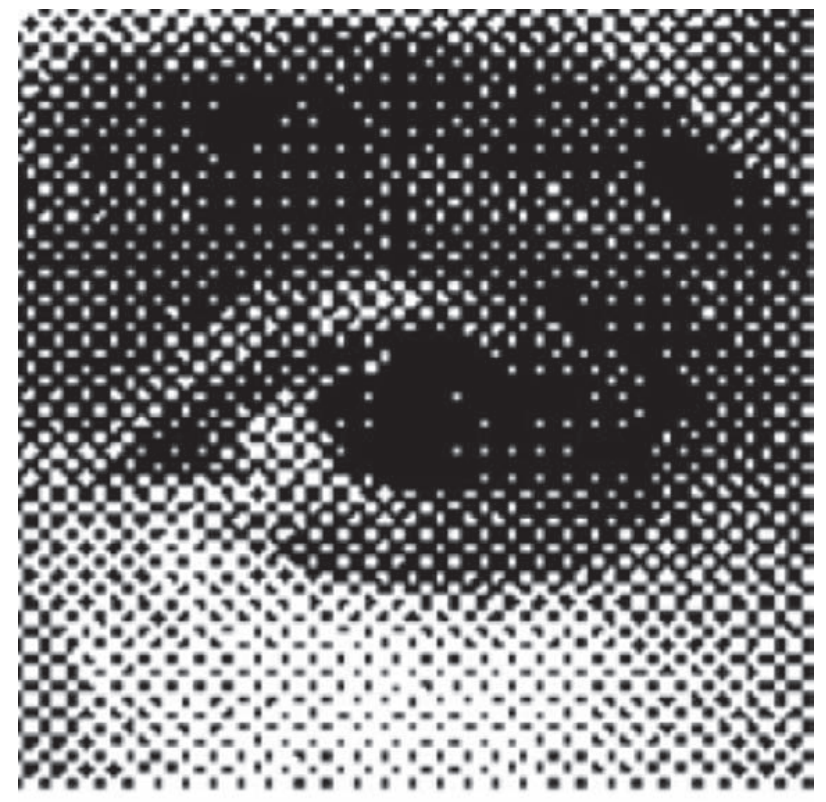

a) Reticulado clássico

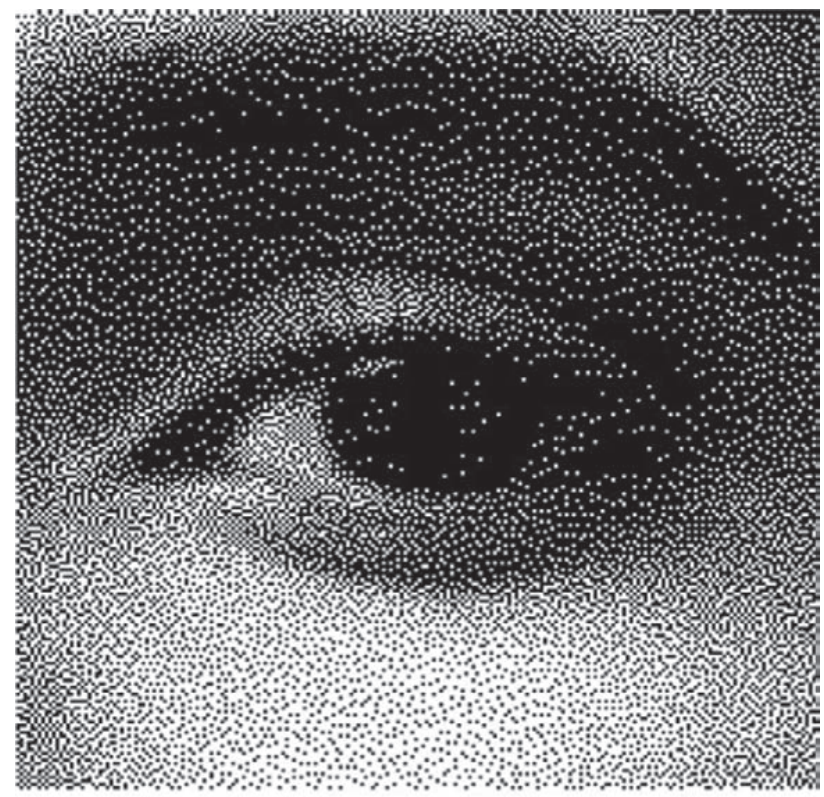

b) Reticulado estocástico

Figura 8. Diferença de aspecto de uma imagem com diferentes tramas: AM (a) e FM (b) ${ }^{12}$. 
Figura 9 mostra o efeito do reticulado (trama) a partir de uma imagem de tom contínuo ${ }^{12-14}$.

Tradicionalmente na serigrafia, devido às limitações tanto das tintas quanto das telas serigráficas, a decoração cerâmica sempre necessitou totalmente do uso de tramas ordenadas ou AM. Com o surgimento da técnica de rotogravura começou-se a utilizar em alguns trabalhos a trama estocástica ou FM, graças ao maior refinamento
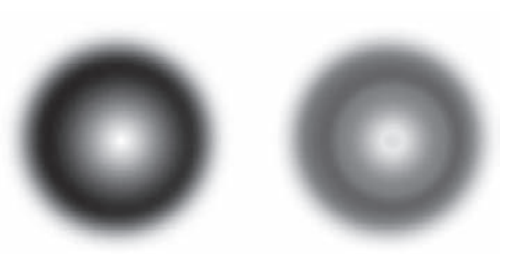

(a)
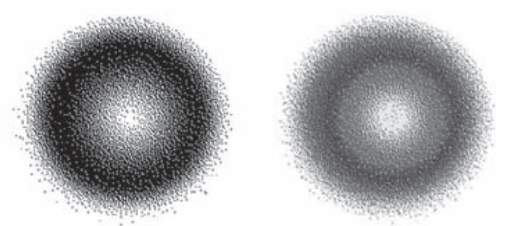

(b)
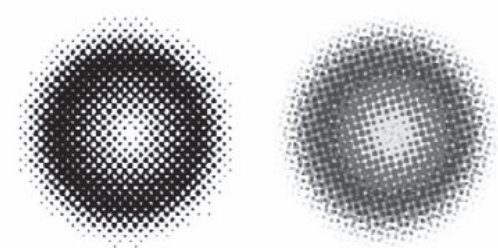

Figura 9. a) Imagem original com tom contínuo; b) reticulado estocástico; c) reticulado ordenado ${ }^{12}$.

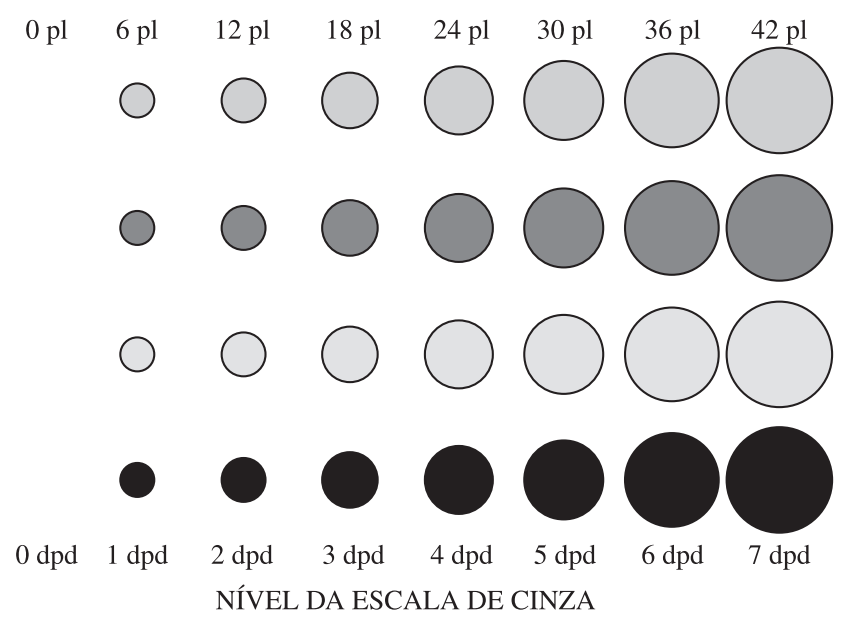

Figura 10. Escala de $\operatorname{cinzas}^{13}$.

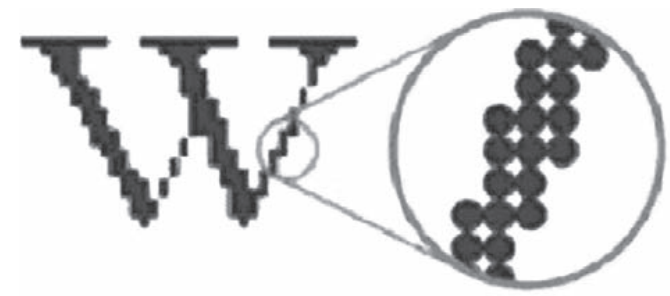

Qualidade impressão de jato de tinta binária das tintas utilizadas. Também houve uma importante melhora na resolução de trabalhos com tramas AM, pois se passou dos habituais $16-18$ pto. $/ \mathrm{cm}^{2}$ a valores próximos a 30 pto. $/ \mathrm{cm}^{2}$ ou mesmo maiores.

A mudança para a tecnologia de jato de tinta leva a uma necessária mudança no tipo de trama, passando-se de uma tradicional trama tipo AM para uma trama estocástica. Esta mudança originou um dos principais desafios tecnológicos para a implantação, pois a necessidade de se imprimir pontos muito pequenos obriga a se dispor de tintas em dissolução (nos primeiros anos) ou tintas pigmentadas (na atualidade) com distribuição de tamanhos de partículas suficientemente baixa, dispersas e sem decantação para que possam sair corretamente pelos injetores ${ }^{10-12}$.

Os novos cabeçotes piezelétricos, grande inovação mundial, foram implementados quase instantaneamente no setor cerâmico. Permitem regular o tamanho de cada uma das gotas que lança um injetor, possibilitando aplicar-se tecnologicamente um novo tipo de trama que combina as características da trama ordenada com as da trama estocástica ${ }^{10-12}$

Este novo tipo de impressão por cabeçote piezelétrico é conhecida como impressão de escalas de cinzas em relação à tradicional, que recebe o nome de impressão binária. Este avanço tecnológico solucionou grandes problemas tecnológicos inerentes ao reticulado estocástico, como são as regiões de baixos e altos tons, assim como a nitidez de detalhes de grande contraste. Nas Figuras 10 e 11 pode-se ver o aperfeiçoamento gráfico dado pela impressão em escala de cinzas em regiões com elevados contrastes ${ }^{12}$.

\subsection{Novos cabeçotes piezelétricos com circulação contínua de tinta}

Um dos principais problemas que existem nas primeiras máquinas de jato de tinta é a obstrução dos bicos, principalmente pela formação de bolhas e/ou partículas sólidas devidas à formação de agregados ou precipitados. Este tamponamento impede que se deposite a quantidade de tinta correspondente no ponto desejado, dando lugar a defeitos (riscos) apreciáveis no produto final ${ }^{15}$.

Este defeito é especialmente crítico com as tintas pigmentadas devido à presença de partículas em suspensão. São várias as razões que levaram ao desenvolvimento e produção destas tintas. Entre elas, destacam-se o incremento de intensidade, de gama cromática, ou mesmo a redução do preço final da decoração. O uso destas tintas pigmentadas, com pigmentos não excessivamente finos, tornou conveniente o desenvolvimento de cabeçotes com sistemas de recirculação que impeçam a precipitação das partículas ${ }^{16}$.

Recentemente foram lançadas no mercado distintas tecnologias patenteadas (Hybrid Side Shooter (HSS ${ }^{\mathrm{TM}}$ ) e TF Technology ${ }^{\mathrm{TM}}$ ) nas quais a tinta circula de forma contínua nos cabeçotes. Tudo com o objetivo de eliminar ou reduzir grandemente estes problemas, e permitindo que o tempo de trabalho sem necessidade de parar a máquina para limpeza dos cabeçotes aumente substancialmente ${ }^{17,18}$.

Para o ótimo funcionamento destes cabeçotes é necessário que as tintas cumpram uma série de propriedades. Por esta razão e pela aparição no mercado de um grande número de empresas que ofertam

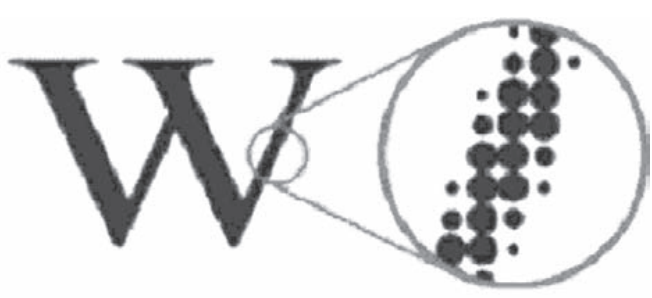

Qualidade impressão de jato de tinta em escala de cinzas

Figura 11. Detalhe da melhora de nitidez obtida com a impressão em escala de cinzas ${ }^{13}$. 

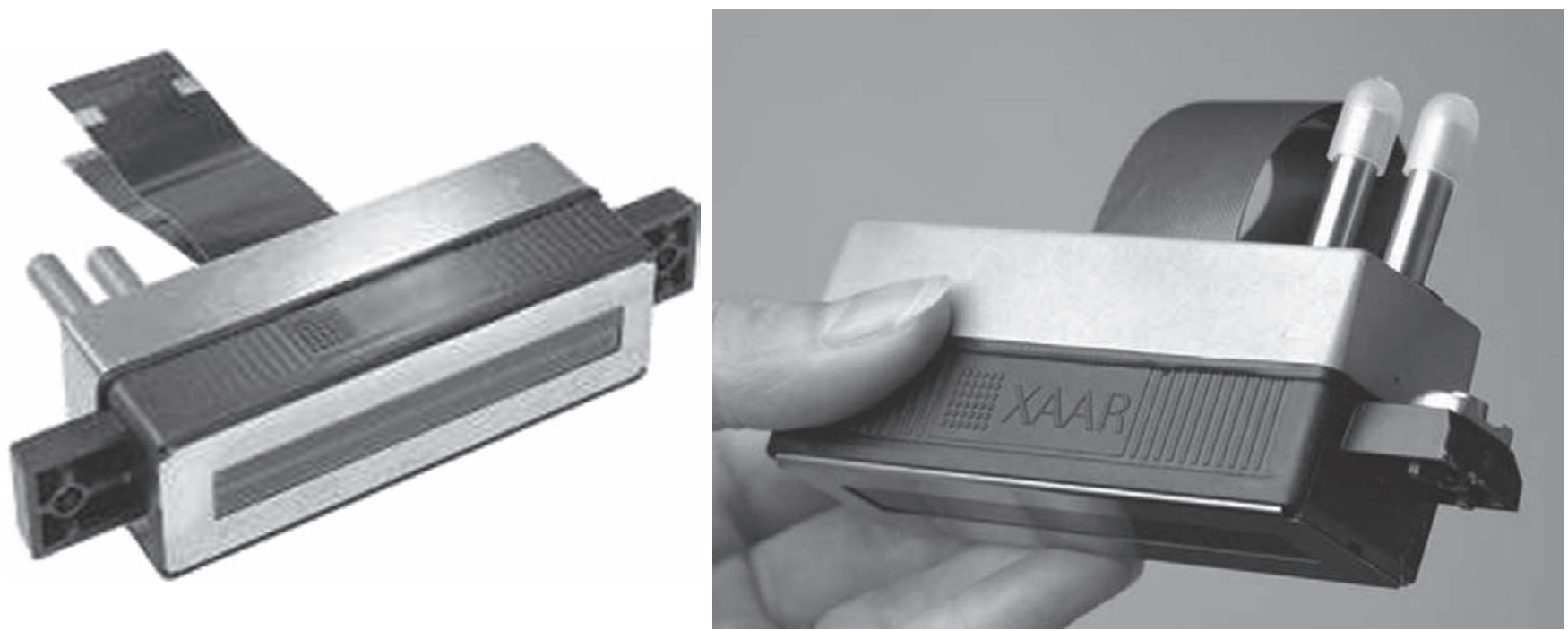

Figura 12. Cabeçote Xaar 1001 com tecnologia patenteada de movimento contínuo de tinta evita a obstrução dos injetores por bolhas ou precipitados ${ }^{19}$.

tintas preparadas para decoração por jato de tinta, as empresas fabricantes de cabeçotes foram obrigadas a estabelecer um rigoroso conjunto de ensaios para as tintas. O caso mais conhecido e que pode servir de exemplo é o da empresa Xaar (Figura 12). Se for adquirida uma tecnologia com cabeçotes Xaar é necessário utilizar tintas previamente certificadas pela empresa. Em caso contrário, a empresa não se responsabiliza por qualquer problema com seus cabeçotes durante o período da garantia. Até outubro de 2010, segundo dados da página web da empresa Xaar, as empresas que oferecem tintas cerâmicas certificadas seriam Ferro, Esmalglass-Itaca, Chemigraff (em colaboração com Fritta) e Colorobbia ${ }^{19}$.

\section{Tintas Empregadas na Tecnologia Jato de Tinta}

As tintas são suspensões utilizadas pelo sistema de impressão para decorar superfícies cerâmicas. Para a obtenção de resultados satisfatórios as tintas devem cumprir requisitos mínimos como, por exemplo, capacidade de colorir o suporte (com auxílio de substâncias corantes), capacidade de transferir a cor e garantir a fixação desta sobre o suporte (aproveitando-se das propriedades dos veículos) $)^{12,15-18}$.

As tintas são compostas principalmente por substâncias corantes, um veículo e outros aditivos. As substâncias corantes podem ser substâncias solúveis no meio de transporte ou pigmentos (pequenas partículas em suspensão). O veículo é o meio no qual o agente corante é dissolvido ou disperso e que serve como meio de transporte do mesmo desde o reservatório de tinta até o suporte. Este meio pode ser água, óleo (glicóis de grande cadeia e/ou hidrocarbonetos) e outros solventes como alcoóis, glicóis e lactatos. Há também outros aditivos com funções determinadas para melhorar as propriedades reológicas das suspensões. São, por exemplo, ligantes, controladores de tensão superficial, eliminadores de espuma, ajustadores de $\mathrm{pH}$, etc ${ }^{18}$.

\subsection{Propriedades das suspensões de tintas}

Como comentado anteriormente, para que a aplicação de uma tinta possa ser realizada de uma forma adequada pelas técnicas de jato de tinta, estas devem apresentar algumas propriedades, algumas das quais são descritas brevemente a seguir ${ }^{17,18}$.

\subsubsection{Viscosidade}

Uma das principais propriedades reológicas das suspensões é sua viscosidade. A viscosidade é a resistência de uma tinta a fluir e depende grandemente da temperatura, pois ao se aumentar a temperatura reduz-se consideravelmente a viscosidade, podendo modificar-se em até $10 \%$ para cada ${ }^{\circ} \mathrm{C}$ de diferença. Esta propriedade define se uma tinta é injetável (válida para o processo) ou não é. Portanto, as suspensões devem estar dentro de um determinado intervalo de viscosidades bem definido, de modo que possam fluir com facilidade através dos cabeçotes ${ }^{17}$.

Para evitar que as variações de temperatura do local de trabalho afetem a viscosidade da tinta e, portanto sua aplicação, as máquinas de impressão devem dispor de um sistema projetado para manter a temperatura constante nos cabeçotes.

\subsubsection{Tensão superficial}

A tensão superficial é definida, de modo geral, como a força que oferece um corpo (tanto líquido quanto sólido) à separação de suas moléculas. No caso dos líquidos, pode entender-se como o trabalho que deve ser realizado para levar as moléculas desde o interior do líquido até sua superfície para criar uma nova unidade de superfície, neste caso para formar as gotas. A tensão superficial define a operacionalidade (formação da gota no cabeçote) e determina em algumas ocasiões a qualidade da impressão ao interagir com o substrato (molhabilidade) (Figura 13) ${ }^{17}$.

\subsubsection{Estabilidade do jato}

A estabilidade do jato de tinta é controlada pelo uso de aditivos, que servem para ajustar o comportamento reológico das mesmas, com o objetivo de se obter gotas de tamanho estável e livres de satélites. Os satélites são pequenas gotas que derivam da principal e que causam um indesejável efeito de aerossol e diminuem a qualidade da impressão (Figura 14). Está intimamente relacionada com a viscosidade, pois o aumento da viscosidade da suspensão aumenta a estabilidade do jato ${ }^{17}$.

\subsubsection{Condutividade}

A condutividade elétrica é definida como a capacidade de um corpo a permitir a passagem de corrente elétrica através de si. A unidade internacional de medida são microsiemens por centímetro $(\mu \mathrm{S} / \mathrm{cm})$. Esta propriedade está diretamente relacionada com a quantidade de sais dissolvidos no caso de tintas aquosas, ou seja, para uma maior quantidade de sais dissolvidos, maior será a condutividade. Portanto, a dureza da água também é muito importante, pois quanto maior for esta, mais elevada será a condutividade devido a maior 


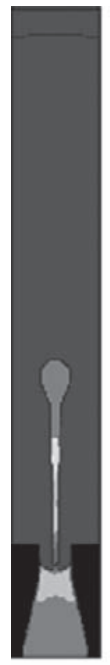

$\mathrm{t}=25 \mu \mathrm{s}$

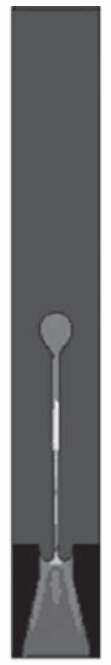

$\mathrm{t}=30 \mu \mathrm{s}$

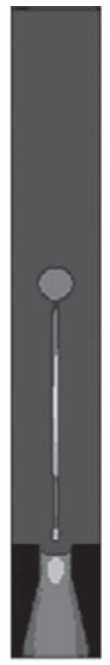

$\mathrm{t}=35 \mu \mathrm{s}$

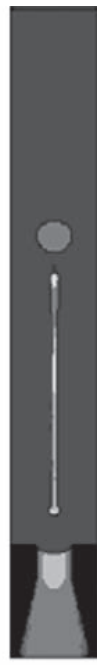

$\mathrm{t}=40 \mu \mathrm{s}$

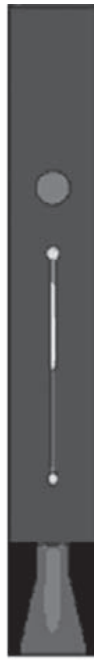

$\mathrm{t}=45 \mu \mathrm{s}$

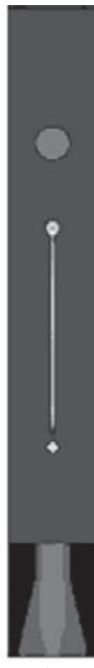

$\mathrm{t}=50 \mu \mathrm{s}$

Figura 13. Simulação de um sistema de jato de tinta comercial ${ }^{17}$.

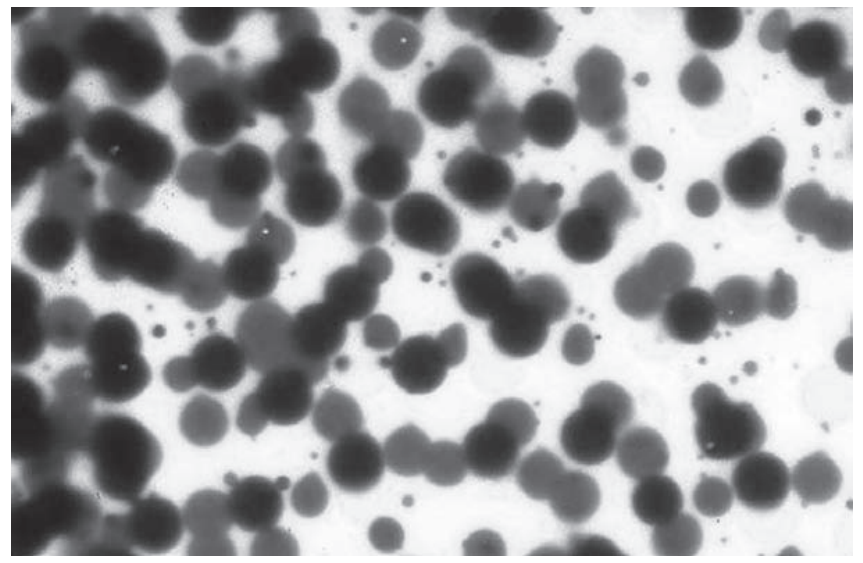

Figura 14. Detalhe de uma impressão por jato de tinta sobre plástico revestido; gotas "satélites" podem ser vistas (aumento de 50X) ${ }^{17}$.

quantidade de sais de cálcio e magnésio dissolvidos, principalmente carbonatos e bicarbonatos ${ }^{17}$.

Com relação aos sistemas de decoração, as tecnologias piezelétricas e térmicas de jato de tinta não requerem condutividade em suas tintas. Entretanto, certa capacidade elétrica das gotas é uma qualidade imprescindível para produzir sua dispersão seletiva pela aplicação de um campo elétrico.

Além de todas estas propriedades há outras propriedades também importantes, como a estabilidade coloidal para evitar a obstrução dos bicos ocasionada pela precipitação dos componentes, por aglomeração ou por aumento de viscosidade; necessidade de $\mathrm{pH}$ neutro para evitar a corrosão dos bicos injetores; e elevado poder corante para utilizar a menor quantidade de tinta a ser depositada ${ }^{17}$.

\subsection{Tipos de tintas}

No mundo das artes gráficas pode-se distinguir entre tintas em dissolução e tintas pigmentadas de acordo com o estado em que se encontram as substâncias corantes dentro da própria tinta. As tintas em dissolução são as mais habituais, apresentam cores mais brilhantes e uma extensa gama de cores, sendo mais econômicas que as pigmentadas. A principal desvantagem que apresentam estas tintas é sua degradação quando expostas à luz, provocando o desbotamento das cores. Por sua vez, as tintas pigmentadas são compostas por pequenas partículas corantes de natureza orgânica e são utilizadas
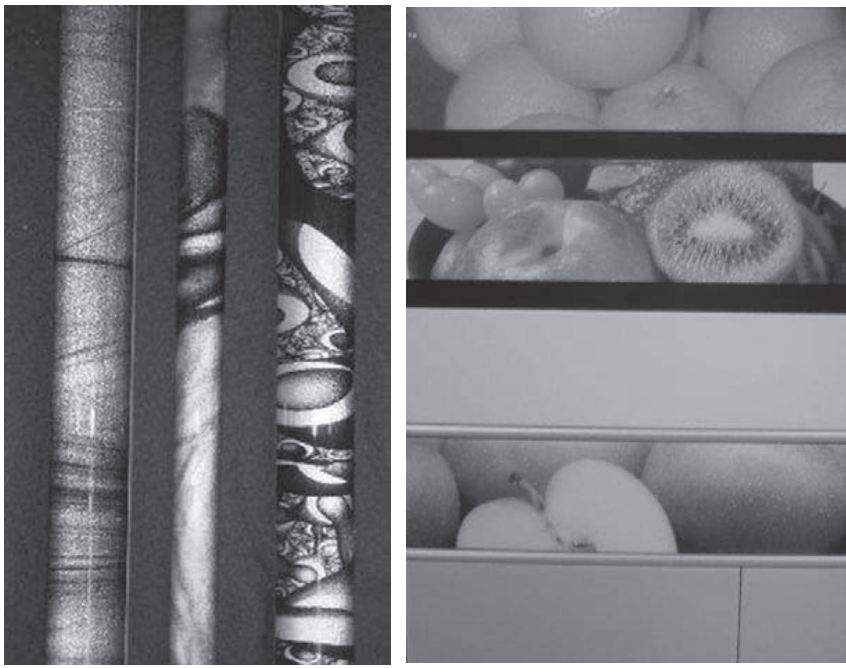

Figura 15. Placas cerâmicas decoradas por impressão por jato de tinta com tintas orgânicas (ITC).

quando se requer uma elevada estabilidade no trabalho realizado ${ }^{18}$ (Figura 15).

Quando se trata de tintas para decoração cerâmica também se pode fazer uma distinção similar, embora sejam grandes as diferenças em relação ao setor de artes gráficas. Em primeiro lugar, a principal diferença está em que as tintas cerâmicas foram desenvolvidas para suportar (tintas pigmentadas) ou desenvolver as cores em temperaturas elevadas, típicas do processo de queima cerâmica, normalmente superiores a $1100{ }^{\circ} \mathrm{C}$ (tintas em dissolução). Com relação às tintas em dissolução, o agente responsável por proporcionar a cor, em lugar de um agente orgânico, é um composto solúvel no veículo que gera a cor a altas temperaturas ${ }^{18}$.

Entretanto, existe uma série de limitações associadas à própria técnica e à natureza dos pigmentos orgânicos usados no setor cerâmico que não permitem a obtenção da tonalidade desejada ao se empregar um processo de quadricromia, somando-se a isto a redução significativa de seu poder corante durante o tratamento térmico a que são submetidos.

Uma alternativa que permite contornar estes problemas é a utilização de tintas preparadas a partir de pigmentos orgânicos dispersos em um veículo polimerizável pela aplicação de radiação UV. Geralmente, as decorações obtidas deste modo são recobertas por um verniz contendo nanocargas, também polimerizável por radiação UV, que confere à superfície decorada durabilidade e resistência ao desgaste. Em conjunto, a utilização destas tintas permite a impressão por quadricromia real, obtendo-se uma decoração de elevada resolução e intensidade de cor, e a possibilidade de dispor de um amplo espaço cromático, além da versatilidade e economia de energia que pode ser obtida no processo de queima ${ }^{17,18}$.

\subsection{Desafios tecnológicos atuais na área das tintas}

Os desafios tecnológicos na área de impressão por jato de tinta compreendem por um lado os relacionados de forma direta com a própria tecnologia (eletrônica, cabeçotes, etc.) e aqueles relacionados às tintas utilizadas. Com relação à eletrônica, exceto em algum caso pontual, o avanço tecnológico está nas mãos das multinacionais com grande experiência no desenvolvimento deste tipo de tecnologia e em grandes laboratórios de $\mathrm{P} \& \mathrm{D}+\mathrm{I}$. Por esta razão, o papel do setor restringe-se à transferência de tecnologia dos possíveis avanços obtidos $^{9-11}$.

Por outro lado, os desafios tecnológicos que afetam diretamente o setor cerâmico estão relacionados com o desenvolvimento e 
otimização das tintas utilizadas. Atualmente, há uma forte dedicação a trabalhos de pesquisa neste campo devido ao interesse econômico das empresas implicadas no fornecimento deste tipo de consumível, com esperança de se obter tintas com melhor desempenho que as da concorrência e assim obter a maior cota possível do mercado.

Alguns dos principais desafios tecnológicos nos quais estão centradas as pesquisas das empresas do setor cerâmico são:9-11

- Melhora da estabilidade coloidal e reológica das tintas;

- Melhora dos sistemas e redução dos custos de produção;

- Otimização da qualidade cromática das tintas primárias;

- Ampliação do número de cores básicas (tintas planas);

- Desenvolvimento de novas fritas e vidrados que permitam melhorar a gama cromática;

- Uso de outros materiais aplicados por jato de tinta (metalizados, propriedades funcionais, etc.).

Caso a tecnologia de jato de tinta experimente o crescimento esperado, não somente as empresas locais diretamente relacionadas com os usuários destas tecnologias (fabricantes de tintas, fornecedores de matérias-primas) irão dedicar-se a esta pesquisa, mas também as grandes multinacionais, que entrarão em jogo com objetivo de monopolizar parte deste mercado.

\section{Conclusões}

Atualmente ainda existem grandes desafios tecnológicos a serem superados na implantação da tecnologia de decoração cerâmica digital por jato de tinta, mas tanto esta tecnologia quanto as tintas utilizadas alcançaram um grau de confiabilidade muito elevado, permitindo a obtenção de excelentes resultados de produção. Com a introdução da tecnologia de impressão por jato de tinta na indústria cerâmica modifica-se drasticamente o antigo processo de desenvolvimento de produto. A nova abordagem oferece diferenças claras que se traduzem em importantes economias de custo, principalmente com a redução ou desaparecimento das provas industriais.

Os desafios tecnológicos na área de impressão por jato de tinta compreendem por um lado os relacionados de forma direta com a própria tecnologia (eletrônica, cabeçotes, etc.) e aqueles relacionados às tintas utilizadas. Por outro lado, os desafios tecnológicos que afetam diretamente o setor cerâmico estão relacionados com o desenvolvimento e otimização das tintas utilizadas, e o crescimento esperado de mercado aumentará a demanda por pesquisa nesta área, não só em empresas locais envolvidas com o setor cerâmico, mas também em multinacionais que entrarão em jogo com objetivo de monopolizar parte deste mercado.

\section{Referências}

1. HUTCHINGS, I. M. Ink-jet printing in micro-manufacturing: opportunities and limitations. In: INTERNATIONAL CONFERENCES ON MULTI-MATERIAL MICRO MANUFACTURE, 2009, Germany: Forschungszentrum Karlsruhe, 2009.
2. KNIGHT, E.; LYNN, C. Industrial inkjet for dummies: xaar special edition. Hoboken: Wiley, 2010.

3. LE, H. P. Progress and trends in ink-jet printing technology. Journal of Imaging Science and Technology, v. 42, p. 49-62, 1998.

4. HEATHER, K. Ampliando horizontes con la impresión digital. Técnica Gráfica 452, p. 6-11, 2007.

5. HOHEMBERGER, J. M. Estudio y desarrollo de pigmentos y colorantes cerámicos "in situ" en vidriados cerámicos, através de métodos no convencionales. 2002 [Tesis doctoral]. Castellón: UJI, 2002.

6. HOSOKAWA, M. et al. Nanoparticle technology handbook. 1. edition. The Netherlands: Elsevier, 2007.

7. MONRÓS, G. Tecnología inkjet en cerámica vidriada. Detail: Revista De Arquitectura Y Detalles Constructivos, v. 4, p. 494-496, 2007.

8. MONRÓS, G. et al. El color de la cerámica nuevos mecanismos en pigmentos para los nuevos procesados de la industria cerámica. 1 . edición. Castellón, UJI: 2003.

9. MONRÓS, G. et al. Tendencias en la innovación de la cerámica plana vidriada aplicada a la construcción. Cerám. Inf. v. 343, p. 107-115, 2007. Edición Especial.

10. OBSERVATORIO tecnológico cerámico. Informe de feira: cevisama 2010. [En línea] Castellón, Instituto de Tecnología Cerámica, 2010. Disponível em: <http://www.observatoriotecnologicoceramico.es/itc/ opencms/itc/es/Mapas/ITF/itc_0012.html>. Acesso em: 08 nov. 2010.

11. OBSERVATORIO tecnológico cerámico. Informe de feira: tecnargilla 2010. [En línea] Castellón, Instituto de Tecnología Cerámica, 2010. Disponível em: http://www.observatoriotecnologicoceramico.es/itc/ opencms/itc/es/Mapas/ITF/itc_0013.html. Acesso em: 08 nov. 2010.

12. GARDINI, D. et al. Nano-sized ceramic inks for drop-on-demand ink-jet printing in quadrichromy. Journal Of Nanoscience and Nanotechnology, v. 8, n. 4, p. 1979-1988, 2008.

13. EFECTS Efficient environmental-friendly electro-ceramics coating technology and synthesis. Disponível em: $<$ http://www.efects.ugent.be/>.

14. BIOINFOBANK Library. In: Development of sol-gel inkjet inks for printing on glass substrates for architectural application (TIGJET). O. O. Chuiko Institute of Surface Chemistry of Nas of Ukraine. Disponível em: <http://lib.bioinfo.pl/projects/view/14432>

15. COLORES CERÁMICOS S.A.; TALLERES FORO, S. L. Decoración digital sostenible de productos cerámicos mediante chorro de tinta continuo y tintas en base agua. Bol. Soc. Esp. Ceram. Vidr. v. 49, n. 2 , p. 139-141, 2010.

16. TOSI, N. Inkjet decoration of ceramic tiles. [En línea] Digitalfire. Disponível em: <http://digitalfire.com/4sight/education/inkjet_decoration_of_ceramic_tiles_344.html $>$. Acesso em: 08 nov. 2010.

17. MARTIN, G. D.; HOATH, S. D.; HUTCHINGS, I. M. Inkjet printing: the physics of manipulating liquid jets and drops. Journal of Physics: Conference Series, v. 105, p. 1-14, 2008.

18. RAGNETTI, M. Ceramic inks for digital decoration. Ceram. World Rev. v. 68, p. 136-139, 2006.

19. XAAR. Disponível em: <www.xaar.com>. 